\title{
Artistic Consumption Behavior of Domestic Tourists for Tourism Performing Arts in Guangxi Zhuang Autonomous Region, China
}

\author{
Jingyuan Cui, Sarana Photchanachan \\ School of Management, Shinawatra University, Bangkok, Thailand \\ Email: 34405037ccbb@163.com, sarana.p@siu.ac.th
}

How to cite this paper: Cui, J. Y., \& Photchanachan, S. (2021). Artistic Consumption Behavior of Domestic Tourists for Tourism Performing Arts in Guangxi Zhuang Autonomous Region, China. American Journal of Industrial and Business Management, 11, 550-565.

https://doi.org/10.4236/ajibm.2021.115035

Received: April 27, 2021

Accepted: May 24, 2021

Published: May 27, 2021

Copyright ( 2021 by author(s) and Scientific Research Publishing Inc. This work is licensed under the Creative Commons Attribution International License (CC BY 4.0).

http://creativecommons.org/licenses/by/4.0/ (c) (i) Open Access

\begin{abstract}
This article aimed to study artistic consumption behavior of tourism performing arts, find out factors influencing consumers to buy tourism performing arts products, improve the product market competitiveness, and increase the market share of cultural enterprises. In this study, 405 domestic travelers with individual behaviors were selected as the research subjects, and a mixed approach was adopted to solve this problem. The results showed that female respondents in Guangxi tourism performing arts accounted for 219 (54.1\%), mainly aged between 30 and 40 years old (51.6\%), bachelor degree accounted for $52 \%$, personal monthly income was relatively average between 4000 and 5000 Yuan. Most of respondents are first-time visitors to Guangxi, with 292 (72.1\%) respondents having experience of watched ethnic tourism performing arts, which indicates that a good viewing experience will have an important impact on their re-purchase. Difference analysis of demographic variables, respondents of different ages, education level, monthly income and profession showed significant differences in their artistic consumption behavior, while those of different genders showed little difference. Through multiple linear regression analysis, product cognition, cultural identity, past behavior, reference group and perceptual behavior control have significant influence on artistic consumption behavior and purchase intention. In addition, all hypotheses have been accepted. Independent variables can influence artistic consumption behavior through purchase intention or directly influence artistic consumption behavior, indicating that consumers' purchase intention is an incomplete intermediary. In order to extend life cycle of tourism performing arts products and maintain the sustainable development of Guangxi's tourism performing arts, through in-depth interviews, respondents put forward the following suggestions after watched Guangxi's tourism performing arts: First, extend the performance time, protect the authenticity of Guangxi's history
\end{abstract}


and culture, and highlight local characteristics; Second, performing arts venues are large, seats are difficult to find, more staff guidance is needed; Appropriately increase the screen, increase online ticket purchase, increase seat selection function, and increase the number of performances; Improving sanitary conditions; Actively deal with complaints and suggestions to improve tourist comfort. Tourism performing arts venues are generally far away from urban areas, supporting facilities and services around performing arts venues are important factors to promote consumers' accommodation at night and improve the economy at night. Third, make full use of media to publicize and promote media platforms such as TV, newspapers, magazines and road publicity platforms to provide authoritative information for the majority of Internet users; Fourth, adjust ticket prices to promote consumer buying.

\section{Keywords}

Tourism Performing Arts, Artistic Consumption Behavior, Guangxi Zhuang Autonomous Region

\section{Introduction}

With the continuous improvement of material living standards, commodity consumption has gradually become the main way of life for people, from daily necessities to consumer durable, from cities to towns, and from the minority to the majority (Fang, 2018). When material life is satisfied, people's demand for culture and beauty will appear (Xu, 2012). Art and cultural tourism becomes an important choice for consumers to realize their spiritual pursuit ( $\mathrm{Wu}, 2015)$. Tourists' demand for travel also gradually changes from traditional sightseeing tourism to diversified tourism experience, which promotes the integration of tourism industry and cultural industry and produces tourism performing arts products (Ma, 2016). Tourism performing art is a new "cultural tourism product" different from traditional tourism products (Zhang, 2010). Ethnic tourism performing art is a new type of "tourism art product" that brings ethnic art from the traditional ethnic life to the stage. It can not only provide a new consumption market for tourists, but also an important factor to promote tourism and economic development in ethnic minority areas (Yang, 2009).

Guangxi is a region with a large minority population and rich cultural resources, which has a good foundation for the development of cultural tourism. In recent years, exchanges and cooperation between Guangxi and ASEAN countries have been increasingly close in the fields of tourism performing arts. From 2015 to 2020, Guangxi sent more than 40 delegations of nearly 1000 people to 10 ASEAN countries to carry out cultural exchanges and cooperation. In 2016, the performance exchange activity of "Liu Sanjie" was carried out, and the performance of "Memory of Hoi an" was performed in Hoi an Ancient city in Vietnam since March 2018, bringing good benefits to the local area (Meng, 2018). There 
are three main types of tourism performing arts in Guangxi: Eternal love series, Impression series and other ethnic performing arts (China tourism bureau, 2018), Mainly concentrated in Nanning, Guilin, Sanjiang, Chongzuo, Laibin and other tourist attractions and ethnic minority areas. According to the analysis of the Department of Tourism and Culture of Guangxi, by December 30, 2018, impression Liu Sanjie, a famous tourist performing art show, had sold 1.62 million tickets in total, with a total box office income of 210 million yuan and a net profit of nearly 100 million yuan. During the May Day holiday in 2019, Nanning Fangte Asean Sacred Painting scenic spot is full of southeast Asian tourism performances, with a total revenue of 14.3 million yuan. The business of these tourist places is usually in the daytime, while the consumption of tourism performing arts can extend the travel time, directly boost the demand for accommodation and other things at night (Zhang, 2010), and promote the consumption growth of the tourism scenic spots at night (Liu, 2007). Tourists are the main consumers (Li, 2013). It is also the most direct participant, and the performance feeling and evaluation generated are the important guarantee for the future operation of tourism performance performance products (Wang, 2017). After tourists implement the consumption behavior, good feelings will promote consumer to make second consumption and carry out word-of-mouth publicity to others, which is conducive to the healthy development of tourism and performing arts. So, consumer behavior is the most direct and effective way to predict whether or not the consumer implements a certain consumption (Fishbein, \& Ajzen, 1975), to clarify the main factors influencing the consumption behavior of tourism performing arts, the purpose is to analyze consumer behavior of tourism performing arts and expand the consumption market (Ajzen \& Fishbein, 1980). Based on the development concept of "demand-oriented", the primary task for tourism performing arts industry to achieve substantial development is to analyze consumer behavior and master the characteristics and rules of tourism performing arts consumption decision-making (Kotler, 2012).

The Guangxi survey does not necessarily reflect the overall picture due to the impact of the epidemic, the short sampling time and the limited number of respondents. In the research, the purpose and content of this study are relatively new, and there are not many literatures and theories for reference. The research conclusions of this paper are also based on the results of a combination of questionnaire survey, data analysis and interview.

\section{Literature Review}

Literature review systematically analyzes variable factors that influence artistic consumption behavior of ethnic tourism performing arts, which lays a foundation for the theoretical model of consumption behavior of ethnic tourism performing arts. Based on planned behavior theory (TPB), this study explored establishment of theoretical model of influencing factors the consumption behavior of ethnic tourism performing arts, and established independent variables 
influencing factors and measurement indicators of artistic consumption behavior of ethnic tourism performing arts. Research on the consumption behavior of tourism performing arts is to study the consumption behavior of tourism performing arts from the category of tourism culture. Due to the particularity of cultural tourism products, consumption behavior of tourism performing arts has both characteristics of general consumption behavior and special law of cultural products. The occurrence of tourism performing arts consumption behavior is a gradual process of development, artistic consumption behavior is result of cognition, emotion, attitude, intention of many factors.

It is found that there are few studies on the artistic consumption behavior, especially on the artistic consumption behavior of tourism performing arts. This study summarizes influencing factors of general consumer behavior, culture and tourism consumer behavior. Based on TPB model, combined with two-factor theory of Kotler in 2012 as the independent variable of this study, the internal factors mainly include product cognition, past behavior and cultural identity. External factors are reference group and perceptual behavior control. Intermediate variable: purchase intention, dependent variable is artistic consumption behavior. This research is carried out from literature analysis, theoretical model construction, empirical research, full text summary, research limitations and future research (See Figure 1).

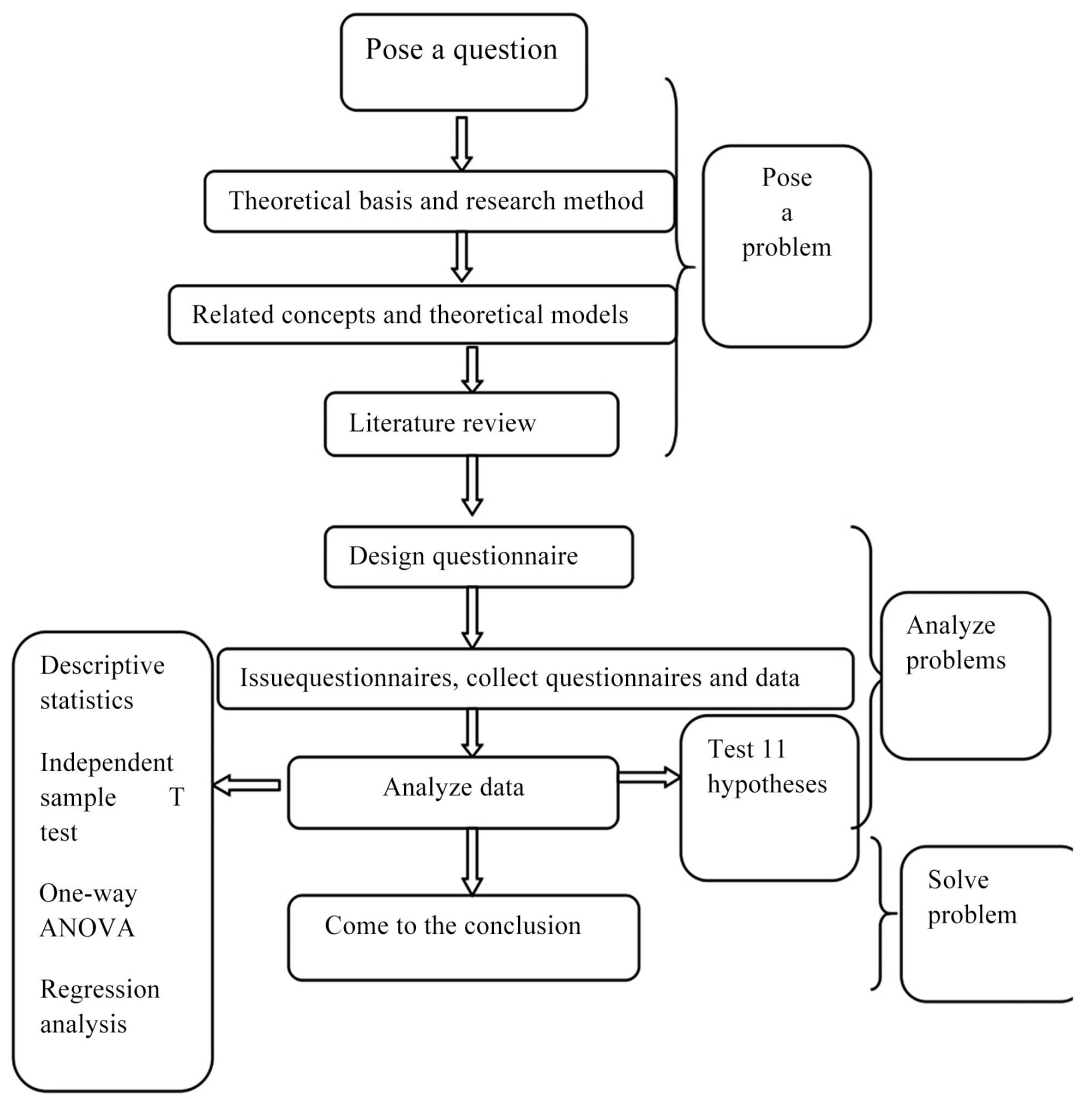

Figure 1. The basic idea and process of this study. 


\section{Research Question and Research Objective}

The sustainable development of tourism performing arts industry depends on tourists $(\mathrm{Xu}, 2009)$. The key to expanding tourism market is to understand the factors that affect consumers' consumption behavior. Specific research questions are as follows:

1) What are the differences in the artistic consumption behaviors of different consumer groups in Guangxi tourism performing arts?

2) Which factors have significant influence on the artistic consumption behavior of Guangxi tourism performing arts?

3) Which factors have significant influence on the purchase intention of Guangxi tourism performing arts consumption?

4) What is the relationship between consumers' purchase intention and art consumption behavior?

5) What suggestions are put forward to promote the sustainable development of tourism performing arts?

Research objectives are as follows:

1) To identify the differences of artistic consumption behavior among different consumer groups.

2) To study consumption behavior and influencing factors of tourist performing arts consumers in ethnic minority areas.

3) To study the purchase intention of tourism performing arts consumers in ethnic minority areas and its influencing factors.

4) To measure the relationship between consumers' purchase intention and artistic consumption behavior, the purpose is to determine whether independent variables can influence artistic consumption behavior through purchase intention, and directly affect artistic consumption behavior; or can only influence artistic consumption behavior through consumers' purchase intention.

5) Based on the results of mixed research (combined quantitative research and qualitative research), provide reference suggestions for the development and marketing of tourism performing arts products. In-depth interviews provide support for theoretical construction and provide detailed information for future consumption behavior research.

\section{Hypothesis and Conceptual Framework}

Based on the literature research, (See Table 1) summarizes five influence factors influencing artistic consumption behavior, author found that: relationship between the five influencing factors and consumer behavior can be divided into three types: first, product cognition, cultural identity, past behavior, reference groups, perceptual behavior control have a direct influence on artistic consumption behavior (Li, 2013). Secondly, five factors namely, product cognition, cultural identity, past behavior, reference groups and perceptual behavior control, influence artistic consumption behavior through consumers' purchase intention, and consumers' purchase intention plays a mediating role (Ajzen \& Fishbein, 1980). 
Table 1. Factors influencing consumption behavior of cultural artworks.

\begin{tabular}{lll}
\hline Number & Authors & Influencing Factors \\
\hline 1 & Schiffman (1987) & $\begin{array}{l}\text { Product, price, promotion, channel, social class, culture, cultural identity, product cognition, perception, } \\
\text { learning, personality, attitude }\end{array}$ \\
2 & Yu (2003) & $\begin{array}{l}\text { Product, price, promotion, channels, social factors (family, social class) cultural identity, subculture, } \\
\text { cognitive factors, emotional state } \\
\text { Cultural identity, demographic environment, social factors (social status, reference group, family, }\end{array}$ \\
3 & Kotler (2012) & $\begin{array}{l}\text { marketing activities, past experience, perception, learning, memory, motivation, personality, mood, } \\
\text { attitude, self-concept, lifestyle, buying needs }\end{array}$ \\
4 & Li (2013) & Artistic cognition, emotional response, volitional control, perceived risk \\
5 & Cao (2017) & Cultural cognition, emotional response, attitude emotion, past behavior, perceived risk \\
6 & Wang (2017) & Tourism performance product quality, cultural identity, tourism experience \\
7 & Huang (2019) & $\begin{array}{l}\text { Emotional state, population, social status, cultural identity, personal experience, reference group, purchase } \\
\text { demand }\end{array}$ \\
\hline
\end{tabular}

Third, five factors, namely product cognition, past behavior, cultural identity, reference groups and perceptual behavior control, can not only directly influence artistic consumption behavior, but also influence artistic consumption behavior of tourism performing arts consumers through consumers' purchase intention. Based on the above analysis, in order to verify the relationship between product cognition, past behavior, cultural identity, reference groups, perceptual behavior control and artistic consumption behavior (Chen, 2006; Zhou, 2011), the following hypotheses are proposed:

$\mathrm{H1}$ : There is significant relationship between product cognition and consumers' purchase intention of tourism performing arts.

H2: There is a significant relationship between product cognition and artistic consumption behavior of tourism performing arts.

H3: There is significant relationship between cultural identity and consumers' purchase intention of tourism performing arts.

H4: There is significant relationship between cultural identity factors and artistic consumption behavior of tourism performing arts.

H5: There is significant relationship between past behavioral and consumers' purchase intention of tourism performing arts.

H6: There is significant relationship between past behavioral and artistic consumption behavior of tourism performing arts.

H7: There is significant relationship between reference groups and consumers' purchase intention of tourism performing arts.

H8: There is significant relationship between reference groups and artistic consumption behavior of tourism performing arts.

H9: There is significant relationship between perceptual behavior controls and consumers' purchase intention of tourism performing arts.

H10: There is significant relationship between perceptual behavior controls and artistic consumption behavior of tourism performing arts.

H11: There is significant relationship between consumers' purchase intention and consumption behavior of tourism performing arts. 
If all the hypotheses are accepted, independent variables can influence artistic consumption behavior through purchase intention, or directly influence artistic consumption behavior, indicating that consumers' purchase intention is an incomplete intermediary; If the verification of $\mathrm{H} 2, \mathrm{H} 4, \mathrm{H} 6, \mathrm{H} 8$ and $\mathrm{H} 10$ fails, it indicates that consumers' purchase intention is a complete intermediary, and independent variables can only influence the artistic consumption behavior through consumers' purchase intention.

These assumptions are converted to null format for formal testing. They will represented by conceptual frameworks (See Figure 2 below).

\section{Methodology}

\subsection{Population}

This study takes domestic individual tourists who have watched Guangxi tourism performing arts as research object. Because past studies have found that most of the performing arts venues in ethnic minority areas are located in scenic spots, Tourism performing arts consumers are $50 \%-60 \%$ group visitors to tourist attractions, and it is a transformation of tourists, not an increment. Individual behavior of tourists is the incremental object of tourism performing arts (Xie, 2016; Wang, 2017). And only the audience who often watch tourism performing arts can make a correct judgment and evaluation on the whole tourism performing arts more objectively. The rich viewing experience also promotes the consumption behavior of tourism performing arts.

This study choose five target market, in Guangxi Guilin, Laibin, Chongzuo and the Sanjiang, five target market based on ethnic minority areas, not only has rich resources of folk music, and it is famous tourist attractions (Wang, 2017) in 2018 , five the number of tourists attractions accounted for $76 \%$ of the total number of Guangxi tourism (China Travel News, 2019).

Five target markets were used for data collection, including:

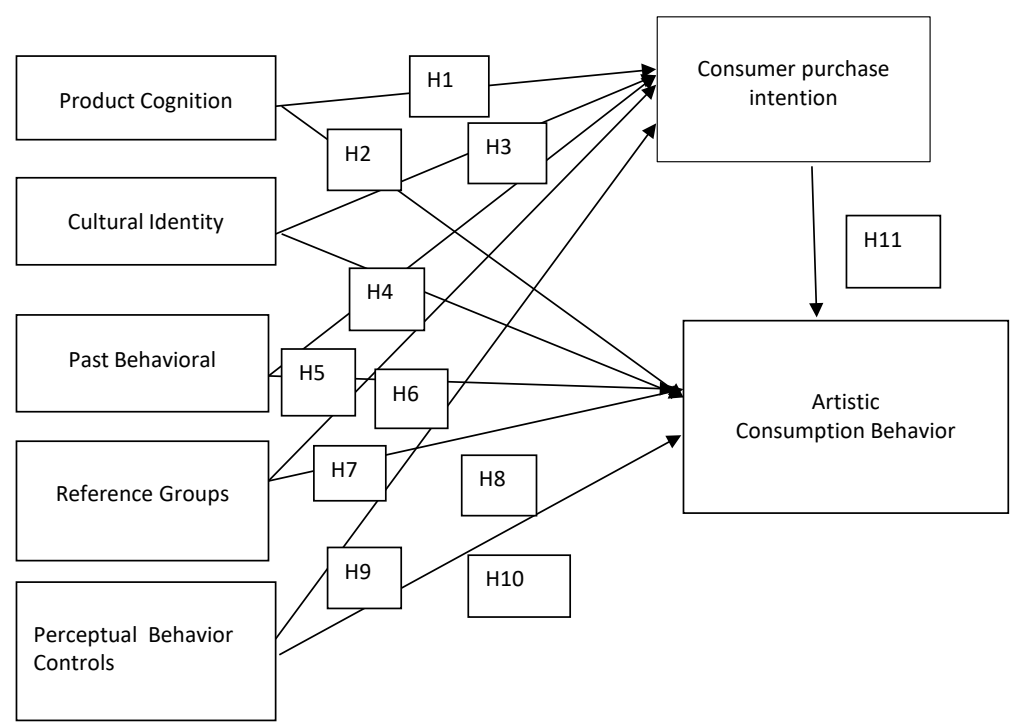

Figure 2. Conceptual framework. 
1) Eternal Love Ethnic Tourism Performing Arts Center, Guilin

2) Liu Sanjie Zhuang Tourism Performing Arts Center, Guilin

3) Jinxiu Yao Nationality Tourism Performing Arts Center, Laibin

4) Huashan Zhuang Tourism Performing Arts Center, Chongzuo

5) Dong Nationality Tourism Performing Arts Center, Sanjiang

Through literature research, Researcher knew that these five target markets are gathering places of ethnic minorities, and their music is well developed. In these places, not only intangible cultural heritage, ethnic music living resources, but also tourism destinations are. There are a large number of tourists in these tourist areas.

\subsection{Sample}

The study selected tourists who watched tourism performances in Guangxi as experimental samples. The questionnaire collected data of individual tourists. As the number of tourists who coming to Guangxi was uncertain, Cochran's uncertain sample size formula was adopted to calculate the sample size to be measured. For this research, 95\% confidence level is selected and therefore the desired level of precision equal to .05 with $Z$ value equal to 1.96 . since the population of tourists are unknown, it is assumed that tourist who coming to Guangxi would participate in the survey, therefore $p$ value equal to .5 . When $Z=1.96, P=.5, e$ $=.05$ using the above formula, the sample size to study is:

$$
n_{0}=\frac{(1.96)^{2} \times 0.5 \times(1-0.5)}{(0.05)^{2}}=384.16 \approx 400
$$

Thus, the sample size is 384 . However, for easy to collect and process the data, the researcher collect data from 400 samples.

In order to ensure effectiveness of questionnaire recovery, the researchers adopted the principles of on-site distribution and on-site recovery. The author was issued questionnaires in five performing arts venues, with 80 copies each. In order to stimulate the desire of respondents to fill in the questionnaire, the respondents were given a small gift before fill in the questionnaire. A total of 400 valid questionnaires were collected in this study.

Qualitative research is adopted, that is, the author conducts on-site interviews and accumulates in-depth data to ensure a comprehensive understanding of the situation and make up for the missing part.

\subsection{Sampling}

The sampling method in this study is purposive sampling. The purposive sampling is to collect respondent's ideas and opinions more specifically, and the collected data can be more realistic and targeted to provide more information for research.

\subsection{Data Collection and Data Analysis}

This study collected 405 questionnaires from domestic tourists who had watched 
Guangxi tourism performing arts. Considering the diversity of tourists, five performance centers were selected for the tour group. Each tourism performing arts centre collects 81 valid questionnaires, Questionnaires were handed out and collected by the researchers themselves. The questionnaire issued from July to September 2020. Researchers used SPSS software to analyze data and calculate results.

\section{Research Results}

\subsection{Demographic Characteristic of Respondents}

Through descriptive analysis, 219 (54.1\%) female respondents in this survey are mainly between 30 and 40 years old (51.6\%), bachelor's degree account for $52.1 \%$, and their income is relatively average between 4000 and 5000 Yuan. Most of tourists are first-time visitors to Guangxi, 292 respondents watched the experience of ethnic tourism performing arts. In addition, $100 \%$ of the respondents have watched tourism performing arts.

\subsection{Descriptive Analysis Results}

According to the questions set in the questionnaire, the interviewees expressed their views on the factors influencing the consumer behavior of tourism performing arts consumers. The results of descriptive statistics show that the perception of tourism performing arts, product price and discount are important factors for consumers to purchase (Schiffman, 1987). The quality of products and services in performance venues is a factor that affects consumers' evaluation of the rationality of ticket prices and whether to buy them (Fang, 2018). Product and service quality of performance venues is a factor that affects consumer purchase (Fang, 2018). Due to the widespread use of the Internet, consumers prefer to buy tickets via the Internet. Respondents in this study believe that understanding local cultural features can help them better understand the ethnic performing arts. Most people compare prices before buying similar products. Suggestions from relatives and friends and propaganda from online media will influence the purchase intention and art consumption behavior. Consumers' time and income level are also limiting factors that limit the purchase of tourism performing arts. Once consumers consider buying tourism performing arts products, they will also recommend them to their relatives and friends. Most interviewees believe that when they have a subjective awareness of purchasing tourism performing arts products, their final consumption behavior will also be affected by objective factors.

\subsection{Hypothesis Testing}

The multiple linear regression analysis found that five variables named (Product cognition, cultural identity, past behavior, reference group, perceptual behavior control) had a significant impact on artistic consumption behavior. Five variables named (Product cognition, cultural identity, past behavior, reference group, perceptual behavior control) have a significant impact on consumers' purchase 
intentions. Moreover, consumers' purchase intention had a significant influence on consumption behavior, which indicates that consumers' purchase intention is an incomplete intermediary, These five independent variables do not necessarily influence consumption behavior through consumers' purchase intention.

First, using consumers' purchase intention as the mediating variable and product cognition, cultural identity, past behavior, reference group and perceived behavior control factors as independent variables, regression was established. The results are shown below:

From Table 2, it can be seen that $\mathrm{F}$ value is equal to 148.727, with significance equal to .000 less than the significant level of .05 , so the regression equation is significant. As can be seen from Table 3, the adjusted $\mathrm{R}$ square value is .651, indicating a good fitting degree of the model. As can be seen in Table 4, VIF values of all variables are below 5 , so there is no collinearity in the model. Under the T-test, the significance of all variables is lower than the significance level, and the standardized coefficient $B$ value of all variables is positive, indicating that product cognition, cultural identity, past behavior, reference group, and perceptual behavior control have significant positive influence on consumers' purchase intention. Therefore, H1, H3, H5, H7 and H 9 are all accepted.

Table 2. Analysis results of the relationship between independent and purchase intention.

\begin{tabular}{|c|c|c|c|c|c|c|}
\hline \multicolumn{7}{|c|}{ ANOVA $^{\mathrm{a}}$} \\
\hline & Model & Sum of Squares & $\mathrm{df}$ & Mean Square & $\mathrm{F}$ & Sig. \\
\hline \multirow{3}{*}{1} & Regression & 170.540 & 5 & 34.108 & 148.727 & $.000^{\mathrm{b}}$ \\
\hline & Residual & 91.504 & 399 & .229 & & \\
\hline & Total & 262.044 & 404 & & & \\
\hline
\end{tabular}

a'Dependent Variable: consumers' purchase intention; 'Predictors: (Constant), behavior control, past behavior, reference groups, product cognition, cultural identity.

Table 3. Result of R Square between independent variable and purchase intention.

\begin{tabular}{ccccc}
\hline Model & $\mathrm{R}$ & $\mathrm{R}$ Square & Adjusted R Square & Std. Error of the Estimate \\
\hline 1 & $.807^{\mathrm{a}}$ & .651 & .646 & .47889 \\
\hline
\end{tabular}

aPredictors: (Constant), perceptual behavior control, past behavior, reference groups, product cognition, cultural identity.

Table 4. Coefficients between purchase intention and independent.

\begin{tabular}{|c|c|c|c|c|c|c|}
\hline \multicolumn{7}{|c|}{ Coefficients $^{\mathrm{a}}$} \\
\hline \multicolumn{2}{|c|}{ Unstandardized Coefficients } & \multirow{2}{*}{$\frac{\text { Standardized Coefficients }}{\text { Beta }}$} & \multirow{2}{*}{$\mathrm{t}$} & \multirow{2}{*}{ Sig. } & \multicolumn{2}{|c|}{ Collinearity Statistics } \\
\hline B & Std. Error & & & & Tolerance & VIF \\
\hline .057 & .117 & & .488 & .626 & & \\
\hline .221 & .078 & .175 & 2.823 & .005 & .229 & 4.368 \\
\hline .210 & .063 & .190 & 3.320 & .001 & .268 & 3.728 \\
\hline .132 & .069 & .119 & 1.986 & .045 & .229 & 4.375 \\
\hline .300 & .064 & .273 & 4.671 & .000 & .256 & 3.910 \\
\hline .137 & .053 & .129 & 2.577 & .010 & .349 & 2.868 \\
\hline
\end{tabular}

aDependent Variable: consumers' purchase intention. 
Second, artistic consumption behavior as a dependent variable, product cognition, cultural identity, past behavior, reference group, perceptual behavior control factors as independent variables to establish the regression equation. The results are shown below:

As can be seen from Table 5, F value is equal to 234.492, significance is equal to .000 is less than significant level .05 , so the regression equation is significant. It can be seen from Table 6 that the adjusted $\mathrm{R}$ square value is .746 , indicating a good fitting degree of the model. As can be seen from Table 7, VIF values of all variables are below 5 , so there is no col-linearity in the model. Under the t-test, the significance of all variables is lower than the significance level, and the standardized coefficient $B$ value of all variables is positive, indicating that product cognition, cultural identity, past behavior, reference group, and perceptual behavior control factors have significant positive effects on artistic consumption behavior. Therefore, $\mathrm{H} 2, \mathrm{H} 4, \mathrm{H} 6, \mathrm{H} 8$ and $\mathrm{H} 10$ are accepted.

At last, regression Analysis of Artistic Consumption Behavior and Consumer Purchase Intention, The results are shown below:

Table 5. Analysis results of the relationship between independent and artistic consumption behavior.

\begin{tabular}{|c|c|c|c|c|c|c|}
\hline \multicolumn{7}{|c|}{ ANOVA $^{\mathrm{a}}$} \\
\hline & Model & Sum of Squares & df & Mean Square & $\mathrm{F}$ & Sig. \\
\hline \multirow{3}{*}{1} & Regression & 130.103 & 5 & 26.021 & 234.492 & $.000^{\mathrm{b}}$ \\
\hline & Residual & 44.275 & 399 & .111 & & \\
\hline & Total & 174.379 & 404 & & & \\
\hline
\end{tabular}

a'Dependent Variable: consumers' behavior; 'Predictors: (Constant), behavior control, past behavior, reference groups, product cognition, cultural identity.

Table 6. Result of R Square between independent variable and artistic consumption behavior.

\begin{tabular}{ccccc}
\hline & & \multicolumn{2}{c}{ Model Summary } \\
\hline Model & $\mathrm{R}$ & R Square & Adjusted R Square & Std. Error of the Estimate \\
\hline 1 & $.864^{\mathrm{a}}$ & .746 & .743 & .33312 \\
\hline
\end{tabular}

aPredictors: (Constant), perceptual behavior control, past behavior, reference groups, product cognition, cultural identity.

Table 7. Coefficients between independent and artistic consumption behavior.

\begin{tabular}{|c|c|c|c|c|c|c|c|}
\hline & \multirow{2}{*}{ Model } & \multicolumn{2}{|c|}{ Unstandardized Coefficients } & \multirow{2}{*}{$\frac{\text { Standazed Coefficients }}{\text { Beta }}$} & \multirow{2}{*}{$\mathrm{t}$} & \multirow{2}{*}{ Sig. } & \multirow{2}{*}{$\mathrm{ViF}$} \\
\hline & & B & Std. Error & & & & \\
\hline \multirow{6}{*}{1} & (Constant) & .454 & .081 & & 5.589 & \multicolumn{2}{|c|}{.000} \\
\hline & product cognition & .283 & .055 & .274 & 5.197 & .000 & 4.368 \\
\hline & cultural identity & .148 & .044 & .164 & 3.367 & .001 & 3.728 \\
\hline & past behavior & .030 & .048 & .034 & 2.637 & .045 & 4.375 \\
\hline & reference groups & .277 & .045 & .309 & 6.203 & .000 & 3.910 \\
\hline & Perceptual behavior control & .143 & .037 & .165 & 3.873 & .000 & 2.868 \\
\hline
\end{tabular}


From Table 8, it can be seen that $\mathrm{F}$ value is 536.812, with significance equal to .000 and less than significant level .05 , so the regression equation is significant. As can be seen in Table 9, the adjusted R square value is .571, indicating a good fitting degree of the model. The adjusted $\mathrm{R}$ square value is .571, indicating a good fitting degree of the model. As can be seen from Table 10, VIF values of all variables are below 5 , so there is no col-linearity in the model. In addition, under the T-test, the significance of all variables is lower than the significance level, and the standardized coefficient $B$ value of all variables is positive, indicating that consumers' purchase intention has a significant positive impact on consumption behavior. Therefore, hypothesis 11 is accepted (See Table 11).

Table 8. Analysis results of the relationship between purchase intention and artistic consumption behavior.

\begin{tabular}{|c|c|c|c|c|c|c|}
\hline \multicolumn{7}{|c|}{ ANOVA $^{\mathrm{a}}$} \\
\hline & Model & Sum of Squares & df & Mean Square & $\mathrm{F}$ & Sig. \\
\hline \multirow[t]{2}{*}{1} & Residual & 74.775 & 403 & .186 & & \\
\hline & Total & 174.379 & 404 & & & \\
\hline
\end{tabular}

aDependent Variable: artistic consumption behavior; b. Predictors: (Constant), consumers' purchase intention.

Table 9. Result of R Square between consumer purchase intention and artistic consumption behavior.

\begin{tabular}{ccccc}
\hline & & \multicolumn{3}{c}{ Model Summary } \\
\hline Model & $\mathrm{R}$ & R Square & Adjusted R Square & Std. Error of the Estimate \\
\hline 1 & $.756^{\mathrm{a}}$ & .571 & .570 & .43075 \\
\hline
\end{tabular}

aPredictors: (Constant), consumers' purchase intention.

Table 10. Coefficients between consumer purchase intention and artistic consumption behavior.

\begin{tabular}{|c|c|c|c|c|c|c|c|c|c|}
\hline \multicolumn{10}{|c|}{ Coefficients $^{\mathrm{a}}$} \\
\hline & \multirow{2}{*}{ Model } & \multicolumn{2}{|c|}{ Unstandardized Coefficients } & \multirow{2}{*}{$\begin{array}{c}\text { Standardd Coefficients } \\
\text { Beta }\end{array}$} & \multirow{2}{*}{$\mathrm{t}$} & \multirow{2}{*}{ Sig. } & \multirow{2}{*}{$\mathrm{ViF}$} & \multicolumn{2}{|c|}{ Collinearity Statistics } \\
\hline & & $\mathrm{B}$ & Std. Error & & & & & Tolerance & VIF \\
\hline \multirow{2}{*}{1} & (Constant) & 1.210 & .087 & & 13.954 & & 00 & & \\
\hline & Consumers' Purchase Intention & .617 & .027 & .756 & 23.169 & .000 & 1.000 & 1.000 & 1.000 \\
\hline
\end{tabular}

${ }^{a}$ Dependent Variable: artistic consumption behavior.

Table 11. Research hypothesis test results.

Hypothesis Results

H1: There is significant relationship between product cognition and consumers' purchase intention of tourism performing arts. Accepted

H2: There is significant relationship between product cognition and artistic consumption behavior of tourism performing arts. Accepted

H3: There is significant relationship between cultural identity and consumers' purchase intention of tourism performing arts. Accepted

H4: There is significant relationship between cultural identity and artistic consumption behavior of tourism performing arts. Accepted

H5: There is significant relationship between past behavioral and consumers' purchase intention of tourism performing arts. Accepted

H6: There is a significant relationship between past behavioral and artistic consumption behavior of tourism performing arts. Accepted 


\section{Continued}

H7: There is significant relationship between reference groups and consumers' purchase intention of tourism performing arts.

H8: There is significant relationship between reference groups and artistic consumption behavior of tourism performing arts.

H9: There is significant relationship between perceptual behavior controls and consumers' purchase intention of tourism performing arts.

H10: There is significant relationship between perceptual behavior controls and artistic consumption behavior of tourism performing arts.

\section{Conclusion}

The results showed that female respondents in Guangxi tourism performing arts accounted for 219 (54.1\%), mainly aged between 30 and 40 years old (51.6\%), bachelor degree accounted for 52\%, personal monthly income was relatively average between 4000 and 5000 Yuan. Most of the tourists are first-time visitors to Guangxi, with 292 (72.1\%) respondents having the experience of watched ethnic tourism performing arts, which indicates that a good viewing experience will have an important impact on their re-purchase. Through the difference analysis of demographic variables, respondents of different ages, education level, monthly income and occupation showed significant differences in their artistic consumption behaviour, while those of different genders showed little difference. Through multiple linear regression analysis, product cognition, cultural identity, past behavior, reference group and perceptual behavior control have significant influence on consumer behavior and purchase intention. In addition, all hypotheses have been accepted. Independent variables can influence consumption behavior through purchase intention or directly influence art consumption behavior, indicating that consumers' purchase intention is an incomplete intermediary.

Through the questionnaire we found that: first, product cognition, product price and promotion discount were important factors influence consumers' purchase of tourism performing arts products. In particular, price, promotion and product quality, consumers believed that the higher the quality of the product, the more obvious consumer behavior. Due to the large investment in the early stage of tourism performing arts and the high ticket prices, consumers also increase the demand for service quality by raising ticket prices. Second, as tourism performing arts in ethnic areas mainly rely on local ethnic culture, consumers believe that understanding local cultural characteristics can help them better understand ethnic performing arts, and understanding the performance content of ethnic tourism performing arts can also help them understand local culture. Third, the suggestions of relatives and friends will affect the purchase intention and consumption behavior. Once consumers consider buying tourism performing arts products, they are also likely to recommend them to their friends and relatives. Fourth, expand the scale of advertising channels, make use of network resources and communication platforms, expand sales channels, and improve consumers' recognition of ethnic cultural products. Consumers' time and income level are 
also limiting factors to purchase tourism performing arts. Consumers generally choose to travel during holidays to realize consumption choices, and consumers also choose appropriate tourism performing arts products according to their income level. Fifth, most respondents believe that when they have the subjective consciousness of purchasing tourism performing arts products, their final consumption behavior will also be affected by objective factors, which can be supplemented by in-depth interviews.

In order to extend the life cycle of tourism performing arts products and maintain the sustainable development of Guangxi's tourism performing arts, through in-depth interviews, the respondents put forward the following suggestions after watched Guangxi's tourism performing arts: First, extend the performance time, protect the authenticity of Guangxi's history and culture, and highlight local characteristics; Second, performing arts venues are large, seats are difficult to find, more staff guidance is needed; Appropriately increase the screen, increase online ticket purchase, increase seat selection function, and increase the number of performances; Improving sanitary conditions; Actively deal with complaints and suggestions to improve tourist comfort. Tourism performing arts venues are generally far away from urban areas, supporting facilities and services around performing arts venues are important factors to promote consumers' accommodation at night and improve the economy at night. Third, make full use of media to publicize and promote media platforms such as TV, newspapers, magazines and road publicity platforms to provide authoritative information for the majority of Internet users; Fourth, adjust ticket prices to promote consumer buying.

\section{Research Limitations}

There are few studies on ethnic tourism performance in the world. Tourism performing arts is a new subject in the study of cultural industry. In this study, we study the factors that influence the purchase intention and consumer behavior of tourism performing arts consumers in ethnic regions. Product cognition, cultural identity, past behavior, reference group and perceived behavior control have great influence on consumers' purchase intention and consumption behavior.

But there are drawbacks:

First, time and funding constraints prevent a broader research investigation.

Second, due to the impact of the epidemic, the sampling time is short and the respondents have limitations. The Guangxi survey does not necessarily reflect the overall picture.

Third, although this study draws on the literature of many scholars, the object and content of this study are relatively new, and there are not too many literature and theories for reference. The research conclusion of this paper is also based on the results of questionnaire, data analysis and combined with interviews.

Fourth, there are some deficiencies in the design of the research scale. This scale according to the consumer behavior as well as the related research of tour- 
ism performing arts, designed the tourists travel acting variable scale the influence of consumer behavior, after preliminary selection of variables, by consulting relevant experts, and make a preliminary investigation, the primary variable correction and adjustment, has a certain theoretical support, but because of the scale is designed and used for the first time, it may still have unreasonable nonstandard parts, may lead to a questionnaire is not reasonable, to a certain extent, affects the quality of the questionnaire. Therefore, at the end of this study, the scale should be modified according to the existing problems, and continue to be used, discussed and modified in the follow-up investigation.

Although, the research is not in-depth enough, and further research is needed. However, the researchers believe that tourism performing arts, as a kind of spacetime art, has a solid humanistic foundation, which can be inherited through tourism and other industries, so that the world can understand China and bring Chinese ethnic culture to the world.

\section{Recommendations for Further Research}

First, in China, the cultural industry to flourish, to establish the performance place, many people in such a market environment, how to make use of the primary source of ethnic culture industry, to build an ethnic of local cultural characteristics, how to improve the market competitiveness of products and the combination of consumer demand, is the focus of future research.

Second, tourism in Guangxi has the obvious difference between peak season and peak season and the deviation of tourist sources. There may be some errors in the results of the study, so the investigation and study with a longer time span can be carried out in the future.

The end, as an important part of art market analysis, the analysis of art consumption behavior of tourism performing arts plays a very important role in market segmentation, target market selection and marketing strategy formulation. This study only puts forward countermeasures and suggestions for the marketing of tourism performing arts, but neglects the art market segmentation and target market selection in the middle of art consumption behavior analysis and marketing strategy formulation. Therefore, it is necessary to conduct further research on the art market segmentation and target market selection of tourism performing arts based on the analysis of art consumption behavior.

\section{Conflicts of Interest}

The authors declare no conflicts of interest regarding the publication of this paper.

\section{References}

Ajzen, I., \& Fishbein, M. (1980). Understanding Attitudes and Predicting Social Behavior (pp. 56-71). Englewood Cliffs, NJ: Prentice-Hall Press.

Cao, N. N. (2017). Research on Art Consumption Behavior of Domestic Big-Budget Films. Wuhan: Wuhan University of Technology. 
Chen, N. (2006). Mechanism Analysis of Mixed Consumption Behavior. Business Research, No. 17, 48-50.

China Tourism Bureau (2018). China Tourism Statistics Bulletin. https://mtop.aizhan.com/48110.html

China Travel News (2019). Guangxi Right. http://www.ctnews.com.cn/news/content/2019-04/10/content 38385.html

Fang, Y. G. (2018). Research on Audience Consumption Behavior (pp. 67, 75). Wuhan: Huazhong University of Science and Technology.

Fishbein, M., \& Ajzen, I. (1975). Belief, Attitude, Intention, and Behavior: An Introduction to Theory and Research (pp. 23-33). Reading, MA: Addison-Wesley.

Huang, D. (2019). Research on the Audience Perception Dimension of Tourism Performing Arts Based on the Grounded Theory-Taking the Love of Song City through the Ages as an Example. Research on Technology Economy and Management, No. 6, 113-117.

Kotler, P. (2012). Principle of Marketing (11th ed.). Hoboken, NJ: Pearson Prentice Hall.

Li, B. (2013). Comparative Analysis of Henan Tourism and Performing Arts Projects. Jintian, 324.

Liu, P. P. (2007). Evaluation Model and Decision Research of Brand Extension (pp. 44-45). Shanghai: Shanghai University of Finance and Economics Press.

Ma, Y. (2016). Research on Evaluation and Development of Inner Mongolia Tourism and Performance Resources. Inner Mongolia: Inner Mongolia Normal University.

Meng, P. (2018). Guangxi: Build “Two Regions” and Build a Bridge of Cross-Border Tourism Cooperation. Ningbo Economic, No. 3, 15-16.

Schiffman, L. G. (1987). Consumer Behavior. Englewood Cliffs, NJ: Prentice Hall.

Wang, J. B. (2017). The Influence of Brand Awareness and Brand Image on Consumers' Purchase Intention. Corporate Research: Theory.

Wu, X. (2015). In-Depth Integration Mechanism of Culture and Tourism and Study on Evolution Model of Cultural Tourism Places (pp. 1294-1306). Nanjing: Nanjing Normal University.

Xie, T. (2016). Research on the Behavioral Intention of Customers Choosing to Stay in Green Hotel-Based on the Theory of Planned Behavior. Journal of Tourism, No. 6, 94-103.

$\mathrm{Xu}, \mathrm{H}$. Y. (2009). History, Form, Pattern and Category of Tourism Performing Arts. China Culture News, 2009-05-15(003).

Xu, Y. M. (2012). Motivation and Personality. Beijing: Renmin University of China Press.

Yang, S. Y. (2009). Influence of Perceived Behavioral Control on Sustainable Consumption Behavior. Changsha: Hunan University.

Yu, Z. (2003). Concept Analysis of Brand Equity and Its Evaluation. Nankai Management Review, No. 1, 10-13.

Zhang, C. (2010). The Role and Value of Large-Scale Live-Action Performance in the Development of Today's Society. Decision-Making Exploration, No. 4, 77.

Zhou, H. L. (2011). Music Marketing and Case Study. Shanghai: Shanghai Conservatory of Music Press. 